\title{
Pregnancy in a Renal Transplant Patient-when unsafe
}

\author{
K Khanam ${ }^{1}$, A Ara ${ }^{2}$, M H Begum ${ }^{3}$, J Rayen ${ }^{4}$, S Khanum ${ }^{5}$, H Rashid ${ }^{6}$
}

${ }^{1}$ Prof. Dr. Khaleda Khanam Professor and Head Dept. of Gynae \& Obs, Arm Forces Medical College (AFMC), Dhaka.

${ }^{2}$ Dr. Anjuman Ara

Colonel, Classified specialist

${ }^{3}$ Dr. Mosha Hafsa Begum

Major, Classified specialist

${ }^{4}$ Dr. Junnu Rayen

Major, Classified specialist

${ }^{5}$ Dr. Shakila Khanum

Major, Classified specialist

${ }^{6}$ Dr. Harunur Rashid

Consultant Surgeon General

Combined Military Hospital (CMH), Dhaka

$2,3,4,5$

Dept. of Gynae \&Obs

Combined Military Hospital (CMH), Dhaka

Correspondence

Major (Dr.) Mosha Hafsa Begum,

Classified specialist

Dept. of Gynae \&Obs, CMH, Dhaka.

Email:hafsakabir99@gmail.com

\section{Introduction}

Renal transplantation restores fertility and increases conception rates in women of reproductive age. The kidney transplant patient who has conceived should keep in 'Safe' throughout the pregnancy period. The 'Safe' includes the mother, the baby and the transplanted organ. The conception rates in dialysis patients with chronic kidney disease is reported as $<1: 200 .{ }^{1}$ After renal transplantation, the pregnancy rate in reproductive age is also reported $12 \% .^{2}$ Some centers prefer waiting two or more years to become pregnant after renal transplantation. This allows for a reasonable amount of time to make certain that transplanted organ is healthy and functioning well. $^{3}$ In this period, a stable condition will be achieved for renal functions and immunosuppressive medications, and the risk of rejection, infection and hypertension will be minimized. ${ }^{4}$ There have been many case series regarding pregnancy in renal transplant patients and their outcome. In one series, pre-eclampsia occurred in $26.4 \%$ and preterm delivery in $26.4 \%$ of the recipients. ${ }^{5}$ Another series showed that $40.7 \%$ resulted in term deliveries, and the rest had preterm deliveries. ${ }^{6}$ Although caesarean section should be reserved for obstetric indications in renal transplanted patients, a case series showed that most of the deliveries performed by caesarean section and those deliveries were premature. ${ }^{7}$

\section{Case report}

A 39 year old woman in her $3^{\text {rd }}$ pregnancy was admitted to Combined Military Hospital (CMH), Dhaka at a gestational age of 33 weeks 4 days on $24^{\text {th }}$ October/2014 with the complaints of headache, increased frequency and burning sensation during micturition along with fever and jaundice. On examination she was febrile, moderately pale, her upper sclera slightly yellow, blood pressure was $140 / 100 \mathrm{mmHg}$, lungs clear and bilateral pedal oedema present (Fig-1).

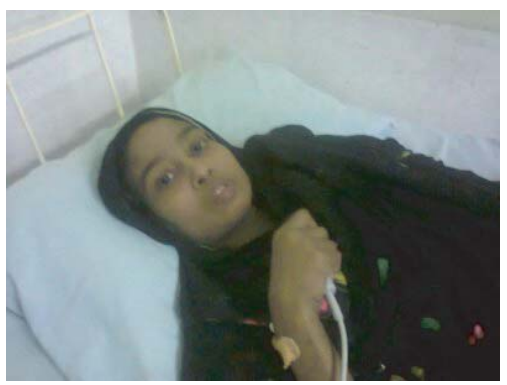

Figure-1: Renal transplant patient (with permission)

Her family history revealed that she is a mother of one female child, who was delivered vaginally at home in 2001. At the end of $2^{\text {nd }}$ pregnancy, she underwent caesarean section at her 26 weeks of gestation due to severe preeclampsia in 2006, but the baby died at 4 days of age. From that time (2006) she had been receiving antihypertensive medication, eventually she developed end-stage renal disease on 2009. She was on regular hemodialysis supervised by an nephrologist. Three years latter, she underwent renal transplantation surgery in December/2012. Since then, she had on several immunosuppressive medications like tacrolimus, azathioprine along with prednisolone and antihypertensive drugs. Her post-transplantation course was uneventful with good renal function (serum creatinine range from 1.1 to $1.2 \mathrm{mg} / \mathrm{dl}$ ). Although she advised not to become pregnant because of possible side effects of pregnancy both for mother and growing fetus. But she had an intense wish to have a male baby. Therefore, she didn't use contraceptive method properly 
and ultimately diagnosed as a case of early pregnancy during her post transplantation follow-up period within one and half year. She was on regular check up under an nephrologist and she consulted with an gynecologist at her 24 weeks of pregnancy and was advised to delivery in a multidisciplinary care unit. As her menstrual cycle was irregular her pregnancy period was calculated by early USG at 8 weeks of gestation and accordingly EDD were found to be on $20^{\text {th }}$ December/2014. She was on irregular antenatal check up. However, last few months of her pregnancy was complicated with repeated urinary tract infection (UTI) and gradual deterioration of renal function and her blood pressure (BP) was uncontrolled. Her serum tacrolimus level was within target level during pregnancy period. Her blood sugar level was increased and she was categorized as gestational diabetes mellitus (GDM), controlled by diet alone. Because of rising serum creatinine level $(3.1 \mathrm{mg} / \mathrm{dl})$ and poorly controlled blood pressure, she was admitted at Dhaka CMH for further management. After admission she was examined thoroughly and monitored by multidisciplinary team comprising obstetricians, nephrologist, urologist and anesthesiologist. Her serum creatinine remained within a reasonable level $(2.3 \mathrm{mg} / \mathrm{dl})$ and $\mathrm{BP}$ was well-controlled, but there was gradual rise of lactate dehydrogenase (1091 micro/L), appearance of Jaundice, serum bilirubin was $2.1 \mathrm{mg} / \mathrm{dl}$ and rising urinary protein creatinine ratio (UPCR) within a short period of time. She was found having a IUGR baby, although Doppler study was normal. She was treated conservatively with betamethasone for fetal lung maturity, with an aim to continue pregnancy. But the baby developed fetal distress and she underwent emergency cesarean section on $6^{\text {th }}$ November/2014 at her 35 weeks of gestation and delivered a male baby weighing about $1.4 \mathrm{~kg}$ (Fig-2).

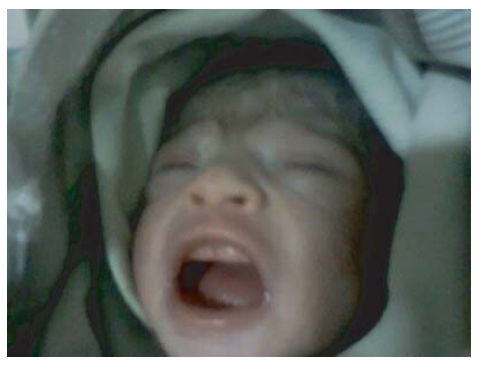

Figure-2 : Newborn baby(1400gms) of renal transplant patient

Apparently the neonate had no congenital anomaly and managed by neonatologist and discharged in healthy state. Patient had been followed up closely and found stable throughout the post natal period.

\section{Discussion}

Transplantation offers a second chance of life for many people with end-stage organ disease. Survival rates have improved over the last 20 years and most of the recipients are healthy and active with an improved quality of life. With appropriate medical care, planning, and close follow-up, successful parenthood is also possible for female and male transplant recipients. The first pregnancy in a transplant recipient occurred in 1958 in a kidney recipient who received a kidney from her identical twin and delivered a healthy male baby. ${ }^{8}$ Since then, there have been thousands of pregnancies in organ transplant recipients throughout the world. Most of the reported pregnancies have happened in kidney transplant recipients.

Patients should be counseled, especially about the opportunity of pregnancy, proper contraception, safety timing for pregnancy, and complications from serious medical condition. Continuation of Immunosuppressive drugs during pregnancy should be discussed properly. The contraception of choice in these populations is still inconclusive. Oral contraceptive pills and injections of depot medoxy progesteroneacetate (DMPA) are highly effective but relatively contraindicated in these patients. Intrauterine device should be considered with caution due to the risk of infection in immunocompromised hosts. Barrier methods are more appropriate in terms of patient's safety but may have higher failure rate. Their failure rate is $12 \%$, but can be as low as $2 \%$ when used consistently. ${ }^{9}$ In the present case report, our patient was not in any hormonal contraception but used barrier method irregularly. The risks of hypertension, preeclampsia, intrauterine growth retardation and premature delivery are higher in these patients, the occurrence of such problems depends on the general medical condition of the recipient. If the transplanted kidney functions well and if the patient has no hypertension or diabetes, the pregnancy progresses to an uneventful manner.

There is limited information about toxicity and teratogenicity of immunosuppressive drugs used during pregnancy in renal transplant patients. The most frequently used drugs in pregnancy are steroids (prednisone and prednisolone) and they can pass through placenta, but maternal-cord blood ratios are about $1: 10 .{ }^{10}$ Cleft palate or mental retardation following inutero steroid exposure are also reported. ${ }^{11}$ Besides, steroid usage at pregnancy is blamed to cause hypertension and increase chance of early rupture of membranes if used in doses of $20 \mathrm{mg} /$ day or above. Our patient had recurrent urinary tract infection and raised blood pressure may be the untoward effect of steroid. Again, azathioprine, another drug used in immunosuppression is reported to cause prematurity, low birth weight, jaundice and respiratory distress syndrome in human studies also compatible of our case. ${ }^{12,13}$

The major concern for our patient is that she became pregnant with in one and half year of post transplantation period and preconceptual counseling regarding maternal and fetal outcome was not possible. Although her renal function was good enough around conception period (1.1 to $1.2 \mathrm{mg} / \mathrm{dl}$ ) and she was on minimum doses of immunosuppressive drugs. Her serum 
creatinine was rising after 33 weeks of gestation and she was admitted with creatinine level of $3.1 \mathrm{mg} / \mathrm{dl}$, uncontrolled blood pressure and with UTI. She was treated conservatively with joint collaboration of obstetrician, nephrologist, urologist, physician and anaestheologist. Her renal function became stable (up to $2.1 \mathrm{mg} / \mathrm{dl})$ but gradual rise of LDH (1091 micro/l), reduction of $\mathrm{Hb} \%(8.6 \mathrm{gm} / \mathrm{dl})$, appearance of jaundice with bilirubin level of $2.1 \mathrm{mg} / \mathrm{dl}$ and development of proteinuria with increased urinary PCR within short period of time.

\section{Conclusion}

Above complications may be attributable due to short interval between transplantation and pregnancy along with poor, irregular antenatal care. Therefore any transplant patient who become pregnant must be on regular antenatal check up, close monitoring by the multidisciplinary team is required to achieve a successful pregnancy outcome.

\section{References}

1. Rizzoni G, Ehrich JHH, Broyer $M$ et al. Successful pregnancies in women on renal transplant therapy. Report from EDTA registry. Nephrol dial Transplant 1992; 7: 279-87.

2. Sturgiss SN, Davison JM. Effect of pregnancy on long-time function of renal allograft. Am J Kidney Dis 1992;19: 167-72.

3. Xu LG, Han S, Liu Y, Wang HW, Yang YR, Qiu F, et al. Timing, conditions, and complications of post-operative conception and pregnancy in female renal transplant recipients. Cell BiochemBiophys2011; 61: 421-26.

4. Trubian A, Zaza G, Rugiu C, Tomei P, Lupo A. Post-renal transplant pregnancy: a project to plan carefully. G Ital Nephrol 2012; 29: 308-2.

5. Ghafari A, Sanadgol H. Pregnancy after renal transplantation; ten-year single-center experience. Transplant Proc 2006; 40 : 251-52.

6. Arei A, Galvao A, Paris MS, Freitas L, Moura P. Outcome of pregnancy in renal allograft recipients. Arch Gynecol Obstel. 2009; 279 : 2737.

7. Picaud JC, Audra P, Putet G, Bellet, Salle BL. Infants born to kidney transplant recipients. Arch for Pediatr $1991 ; 48:$ 323-7.

8. Murray $\mathrm{JE}$, Reid $\mathrm{DE}$, Harrison $\mathrm{JH}$ et al. Successful pregnancies after human renal transplantation. N Eng J Med 1963; 269: 3.

9. Watnick $S$, Rueda J. Reproduction and contraception after kidney transplantation. Curr Opin Obstet Gynecol 2008; 20: 308-12.

10. Beitins JZ, Bayard F, Ances JG et al. The transplacental passage of prednisone and prednisolone in pregnancy near term. J Pediatr1972 81:936-45.

11. Chabria S. Aicardia Syndrome: are corticosteroids teratogens? Arch Neurol1981;38:70-74.

12. Davison JM, Dellagrammatika SH, Parkin JM. Maternal azathioprine therapy and depressed haemopoiesis in the babies of renal allograft patients. Br J Obstet Gynecol 1985; 92:233-39.

13. Munoz-Flores-Thiagaralan KD, Easterling T, Davis C, Bond EF. Breast-feeding by a cyclosporine treated mother. Obstet Gynecol 2001; 97:816-18. 